\title{
ESQUEMA GRÁFICO PARA APORTE TEÓRICO DE UMA DISSERTAÇÃO EM ENGENHARIA - UMA ABORDAGEM EM DESIGN INSTRUCIONAL
}

\author{
GRAPHIC SCHEME FOR THEORETICAL SUPPORT OF A DISSERTATION IN \\ ENGINEERING - AN APPROACH IN INSTRUCTIONAL DESIGN
}

Leandro do Nascimento Vieira de Souza ${ }^{1}$, M.Sc.

André Luís Policani Freitas², D.Sc.

\begin{abstract}
(1) IF Fluminense - Instituto Federal Fluminense / Campus Campos Centro / ARTDECO e-mail: iff.leandro@gmail.com
\end{abstract}

(2) UENF - Universidade Estadual do Norte Fluminense Darcy Ribeiro / LEPROD

e-mail: andrepolicani@yahoo.com

Design, Interdisciplinaridade, Gráfico

Os modelos encontrados em trabalhos, artigos, livros e defesas de pesquisa na área das Engenharias são expressões gráficas de sistemas e de pensamentos. O setor das Engenharias demanda - dos pesquisadores e dos profissionais uma habilidade à parte de se trabalhar com design instrucional sem que estes se deem conta. A eficácia dos sistemas visuais para os engenheiros tornados públicos-alvo destes modelos, no entanto, é restrita aos conhecedores específicos dos conteúdos, porém, nem sempre as estruturas gráficas condizem com o discurso verbal ou com o valor da inovação proposta pelos autores na busca de avanços do Conhecimento. O presente artigo adaptado para uma abordagem em design apresenta um Esquema Gráfico demonstrador de teores reais de uma dissertação de mestrado em Sistema de Gestão, onde a interdisciplinaridade ocasionou sua existência como solução para a parte de revisão de literatura. As defesas textuais deste trabalho são teóricas e conceituais para a melhor adequação ao tema; e a justificativa concerne aos estudos de interesse dos profissionais de Design.

\section{Design, Interdisciplinary, Graphic}

The models found in papers, articles, books and research defenses in the field of Engineering are graphical expressions of systems and thoughts. The sector of engineering demands - from the researchers and professionals - a skill apart from working with instructional design without the professionals realizing it. The effectiveness of visual systems for the engineers transformed into target groups of these models, however, is restricted to specific knowledge of the contents. Nonetheless, not always are the graphic structures consistent with the verbal discourse or the value of innovation proposed by the authors in search of knowledge advances. This article, adapted to an approach in design, features a graphic scheme which shows real data based on a master's thesis in Management System, where interdisciplinarity caused its existence as a solution to part of the literature review. The framework of this study is theoretical and conceptual for a better approach of the theme; and the justification regards to studies of interest to professionals in design. 


\section{$16^{\circ}$ \\ ERGODESIGN USIHC CINAHPA}

\section{Introdução}

O designer gráfico que trabalha com pesquisas interdisciplinares, encontra a diferenciação de sua atividade por meio de abordagens advindas de profissionais e acadêmicos de outras áreas. Observa-se que, em design instrucional, soluções podem ser encontradas para a melhoria de gráficos e sistemas visuais, e aplicadas diretamente aos resultados de trabalhos no campo das Engenharias, por exemplo. Uma vez que, o "modelo" é comunicação vital para existência de apresentações de qualidade dos conteúdos deste campo.

Conforme concluiu as engenheiras Lia e Marília num artigo sobre uso estratégico de gráficos no âmbito das organizações:

Os gráficos desempenham papel importante
no contexto organizacional, tanto como
processo de construção de conhecimento
coletivo, como representação codificada deste
conhecimento. Algumas das principais
funções dos gráficos dentro das organizações
são: (...) auxiliar a visualização de sistemas
complexos, atuar como base comum para
discussão, de modo claro e direto, estimular a
memorização dos conteúdos, possibilitar a
recuperação de conteúdos, e compartilhar
vocabulários. [Krucken e Costa, 2005]

Os designers que se habilitam em hierarquia de informação seja para expressão de uma empresa, ou para expressão de um conteúdo, fazem escolha seletiva e apropriada de elementos gráficos. Muitos esquemas - tidos como resultados efetivos de pesquisas nas mais diferentes áreas - podem ser melhorados quanto ao visual e quanto à significação de suas partes integrantes. A questão é demonstrar a partir de um esquema gráfico de que maneira pode existir a veiculação do entendimento por meio visual, nas áreas do Conhecimento onde a palavra "modelo" tem grande valor como expressão de resultados.

\section{Objetivos}

O objetivo geral é fazer uma abordagem em design instrucional sobre os detalhamentos de um $16^{\circ}$ Ergodesign - Congresso Internacional de Ergonomia e Usabilidade de Interfaces Humano Tecnológica: Produto, Informações Ambientes Construídos e Transporte

$16^{\circ}$ USIHC - Congresso Internacional de Ergonomia e Usabilidade de Interfaces Humano Computador

CINAHPA | 2017 - Congresso Internacional de Ambientes Hipermídia para Aprendizagem.

esquema gráfico real construído por um dos autores para a parte de revisão de literatura de uma dissertação interdisciplinar. Os objetivos específicos pautam em: pormenorizar teores específicos para habilitação à compreensão do referido esquema posicionando-o como "aporte teórico" do presente artigo; e identificar os elementos visuais mais adequados quanto à sua significação, como os "resultados" deste trabalho.

\section{Metodologia}

Após levantamento teórico feito em design instrucional a cerca das funções básicas, metas e instrumentalização desse campo do Design - no que tange a geração de sistemas gráficos para aprendizagem a partir da visualidade dirigida de informações - foram consultadas outras fontes (artigos) e livros para formar a base de conteúdos integrantes sobre abordagens de sistemas parecidos e também postos em análise como melhoria na comunicação visual de dados.

\section{Aporte teórico}

A revisão de literatura da dissertação referencial que fomentou a existência do Esquema Gráfico tornou-se foco das abordagens instrucionais deste artigo. De forma breve, começa-se a seguir uma abordagem que tem como função: deixar bem discernidas as três diferentes áreas tangenciadas pela pesquisa: Marca, Produto e Consumidor.

Como introdução, explana-se sobre Gestão e Necessidade - uma vez que o trabalho referenciado versou sobre um avanço no campo da gestão quanto à forma de captação de opiniões de compradores que respondem uma pesquisa específica no campo da produção de automóveis. A Engenharia se serve dos detalhamentos de pesquisas em atendimento ao consumidor para que as indústrias inovem nos processos de geração dos produtos.

a) MARCA (região inferior do Esquema Gráfico apresentado em Resultados): Se forem colocadas sob o status de Organizações, todas as fábricas do ramo automotivo dentro do universo sem fim de 


\section{$16^{\circ}$ \\ ERGODESIGN USIHC CINAHPA}

todos os tipos de produtos que hoje são gerados pela indústria de uma maneira geral em todos os cantos do planeta - o foco ocorre no campo da Gestão.

b) PRODUTO (região central do E.G.): Se forem colocadas no status de produtos, todos os modelos de automóveis produzidos em todo o planeta, o foco ocorre no campo da Necessidade das pessoas, no específico do ato pessoal de aquisição de um meio para transporte em ambiente urbano.

c) CONSUMIDOR (região superior do E.G.): Quando se une Gestão (marca, nome da empresa) de uma organização com a Necessidade (produto, demanda) das pessoas, ocorre a origem de um núcleo complexo de conteúdos cujo recorte é a constituição do tema e dos objetivos da pesquisa feita para formação da dissertação: o consumidor atrás "da lente" do marketing fechando todo um pensamento sistêmico. Não há produto se não houver demanda.

A própria hierarquização das palavras no Esquema Gráfico que será apresentado em Resultados, demonstra a importância dada às três áreas cujo foco central é o produto e os focos periféricos são o consumidor e a marca.

O consumidor foi colocado no topo do Esquema Gráfico para emblemar o teor da pesquisa neste sistema visual. Conforme está sedimentado - de modo bem amplo - nas palavras de um reconhecido historiador brasileiro no campo da História do Design:

O pensamento sistêmico corresponde, em sua essência, à lógica da indústria. Beneficiamento e aproveitamento, gestão e logística, organização de muitas partes em um sistema cada vez mais integrado. Não é à toa que o design, por ser fenômeno da era industrial, reflete este tipo de pensamento, em sua maneira de abordar o mundo [Cardoso, 2012:244]. $16^{\circ}$ Ergodesign - Congresso Internacional de Ergonomia e Usabilidade de Interfaces Humano Tecnológica: Produto, Informações Ambientes Construídos e Transporte

$16^{\circ}$ USIHC - Congresso Internacional de Ergonomia e Usabilidade de Interfaces Humano Computador

CINAHPA | 2017 - Congresso Internacional de Ambientes Hipermídia para Aprendizagem.

Por outro lado, gerir uma organização demanda conhecimento sobre sistemas de gestão; enquanto a necessidade das pessoas demanda, em última análise, conhecimento sobre como são fabricados os produtos para os diferentes públicos-alvo; e em análise intermediária, interessa saber o que as pessoas percebem, têm expectativa e querem encontrar naquilo que compram.

A respeito das marcas, existem questões que as referenciam como preponderantes no ato de escolha de um novo automóvel. A respeito do produto existem outras questões que o referencia quanto à função e à estética.

Mas, a respeito dos consumidores quanto ao que eles percebem de valor - existem verificados, no mínimo, dois campos de desenvolvimento teóricoprático na literatura vigente: campo afetivo (emocional) por Mont'Alvão (2008) em trabalho publicado sobre ergonomia afetiva; e o campo racional (cerebral) por Batey (2010), em sua abordagem sob título: "O Significado da Marca" onde ele investiga com dados da neurociência, de que maneira as marcas (nomes de fabricantes e de produtos) vigoram na memória dos consumidores.

Nos últimos anos, os núcleos específicos tanto de acadêmicos (professores) quanto de gestores (profissionais), têm estabelecido títulos similares entre si, para suas colaborações significativas em termos de gestão e necessidade, atrelando o atendimento pleno do consumidor à uma estratégia preponderante dentro do meio empresarial. Por exemplo, "Gestão Estratégica do Design", que é o título de um trabalho de Brunner e Emery (2010); bem como, "Design Thinking Brasil", que é outro título de trabalho elaborado por Pinheiro (2011). Trata-se de dois longos estudos acerca de práticas, cases reais (relatos de aplicação prática), onde demonstra-se que a gestão de uma organização tem fatores passíveis de serem conectados com a necessidade dos consumidores dos produtos oferecidos por esta organização.

A dissertação em si visa identificar e classificar atributos observados pelo usuário de automóvel. Usuário este, que foi tornado respondente pelo instrumento (questionário quali-quantitativo). Este 


\section{$16^{\circ}$ \\ ERGODESIGN USIHC CINAHPA}

artigo, portanto, em si, visa discorrer sobre os elementos visuais e suas interrelações gráficas para que as áreas diferentes encontrem distinção no contexto multidisciplinar da abordagem. O que segue nas próximas linhas é uma outra descrição sobre marca, produto e consumidor - palavras tornadas basilares desde a geração do Esquema Gráfico tornado objeto para este trabalho.

Vale registar que, quanto à Gestão e Necessidade, mesmo já referenciadas anteriormente, são termos importantes sim, mas que aparecem expressos por meio da escrita de duas novas palavras que integram o mesmo gráfico: Marketing e Design. Consumidores + Produto + Marca - torna-se a fórmula-chave do design instrucional do Esquema Gráfico por dar significado aos sinais de soma. O primeiro sinal de soma é o marketing (no que tange à propagação dos diferenciais que o produto tem, perante o consumidor); e o segundo sinal de soma é o design (no que tangencia ao projeto e também aos aspectos visuais que atraem o gosto do comprador bem como fatores simbólicos que são levados em conta pela fábrica no ato do projeto e produção do automóvel).

Não decorre de fatos conclusivos, não são dados de conhecimento comum a todos, mas do termo Marca para o termo Consumidores uma reta branca foi utilizada para representar essa importante ligação de extremos da produção, quem fabrica e quem consome. Pois, no argumento da defesa visual para esta escolha, pode-se dizer que a reputação positiva ou negativa de uma marca automotiva está ligada ao novo produto que ela lança para consumidores comprarem e tornarem-se satisfeitos ou não.

Utilizando a mesma estratégia em design, a Marca passa a ter uma relação de ida e de vinda com o Consumidor, seja com a reputação positiva ou negativa do Produto. Por sua vez, a Marca está atrelada ao gosto do publico comprador pelas vias do design e mais além: pela satisfação e pela percepção mensuráveis. Sobre a importância disto em nossa sociedade, um designer a respeito da produção industrial, assim escreveu: $16^{\circ}$ Ergodesign - Congresso Internacional de Ergonomia e Usabilidade de Interfaces Humano Tecnológica: Produto, Informações Ambientes Construídos e Transporte

$16^{\circ}$ USIHC - Congresso Internacional de Ergonomia e Usabilidade de Interfaces Humano Computador

CINAHPA | 2017 - Congresso Internacional de Ambientes Hipermídia para Aprendizagem.
O Design, sob uma ampla visão, se reconhece integrado ao processo de evolução humana, no sentido de ser um mediador da produção existencial do homem. Isto é, em seu processo de humanização, em sua busca de satisfazer necessidades próprias, que se materializam no e pelo trabalho, e que, para tanto, procura criar um mundo artificial sob um fazer de viés criativo. Da mesma forma, faz-se necessário recordar que o campo do Design Industrial, por definição, nasceu da divisão social do trabalho, em meio às contradições da sociedade industrial; pela necessidade de um tipo específico de atividade profissional que pudesse adequar o desenvolvimento e a produção dos produtos oriundos dessa com o progresso tecnológico que ora se implantara [Esquef, 2011:89]

As ponderações a cerca do Esquema Gráfico uma vez concluídas aqui, ajudam a interpreta-lo a partir do senso comum que se tem sobre o mundo industrial e a sociedade, seus costumes e sua cultura material.

\section{Resultados}

Trata-se de uma estrutura visualmente assimétrica chamada de Esquema Gráfico com função de análise dos teores de revisão de literatura para uma dissertação de mestrado na área de Sistemas de Gestão (Marketing e Produto).

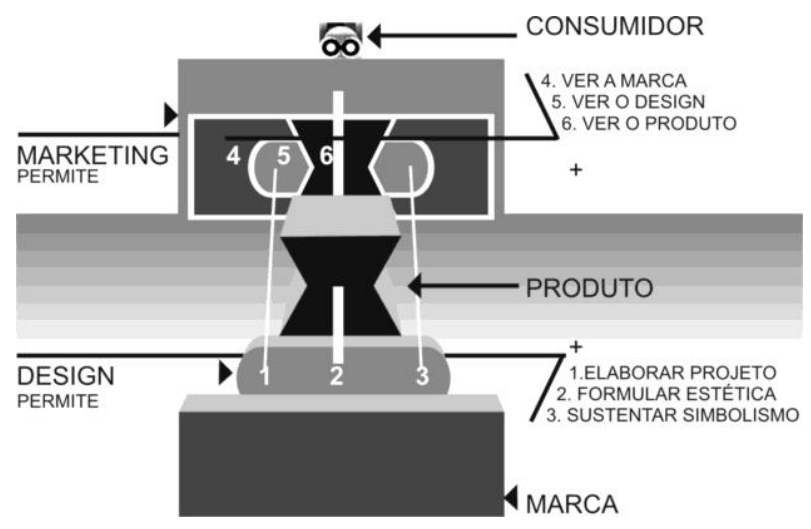

Figura 1: Esquema Gráfico (E.G.) Fonte: Autoria própria 


\section{$16^{\circ}$ \\ ERGODESIGN USIHC CINAHPA}

$16^{\circ}$ Ergodesign - Congresso Internacional de Ergonomia e Usabilidade de Interfaces Humano Tecnológica: Produto, Informações Ambientes Construídos e Transporte

$16^{\circ}$ USIHC - Congresso Internacional de Ergonomia e Usabilidade de Interfaces Humano Computador

CINAHPA | 2017 - Congresso Internacional de Ambientes Hipermídia para Aprendizagem.
Construída para facilitar a acomodação teórica dos mais diversos conteúdos interdisciplinares, esta estrutura visual comporta alguns conhecimentos na área de design informacional no que tange a compreensão do significado e das funções intermediadas pelas razões de ordem específica.

\section{Compreender o Esquema Gráfico assim} constituído é efetivar uma leitura diferenciada - e visualmente condensadora - a respeito do "cenário" dos mais diferentes textos que precisaram ser consultados, lidos e resenhados pelo autor para a execução da pesquisa que gerou a dissertação. Em termos gerais, a temática do atendimento ao consumidor de produto automotivo foi abordada no intuito de apresentar resultados de uma pesquisa feita pelo autor do trabalho e também deste artigo, junto aos usuários e/ou motoristas de carros de passeio. Campos do Design, Administração, Engenharia e Gestão encontram-se mencionados a partir das cinco palavras-síntese contidas no gráfico: consumidor, marketing, design, produto, marca.De uma forma geral, o Design (retângulo horizontalizado cinza claro com laterais semicirculares) permite elaborar o projeto, formular a estética do produto e sustentar o simbolismo que cerca este produto. Por sua vez, o Marketing (sendo outro elemento visual - janela retangular de outline branca) permite -

graficamente - ao consumidor ver a marca, ver o design e ver o produto. Com esse dualismo elaborado com esta finalidade, constituíram as partes superior e inferior do sistema gráfico.

Na parte superior está o Consumidor olhando de frente para o produto (sólido de ilusão tridimensional em forma de ampulheta) por meio de uma reta branca espessa que desce de uma janela retangular de outline branca (Marketing). Observa-se que, junto com o produto (item 6) estão os elementos visuais que significam o design do mesmo (item 5) e o design da marca da fabricante (item 4).

Na parte inferior do gráfico está a Marca (nome de um fabricante de automóveis na forma de um retângulo cinza-escuro) "olhando" para o produto que, por sua vez, está ligado aos olhares do Consumidor por meio da continuação da reta branca espessa. Junto com o produto visto de costas, está a função de elaborar projeto (item 1) e a meta de sustentação de todo o simbolismo que a marca carrega (item 3) perante o que está na mente dos consumidores, dentre valores e defeitos que vem à lembrança quando a marca é mencionada. Consumidor, produto e marca são os principais itens de uma das partes constituintes da dissertação e, por isso, são palavras apresentadas na forma de letras em caixa alta. Marketing e Design são somatizadas graficamente com mesma grafia, porém com mesma linha visual de base, formada pelos caracteres da palavra "permite" que é apresentada duas vezes.

A mecânica visual do Esquema Gráfico funciona ora ascendente centralizada, ora descendente centralizada conforme delineamento dos conteúdos condizentes e de ordem específica. Se o

Consumidor pode ver a marca através do produto (itens 4,5 e 6), a Marca procura atender os anseios deste Consumidor apresentando um produto de qualidade fruto de bom projeto, boa estética e boa sustentação simbólica de valor (itens 1, 2 e 3). A gestão aplicada à produção do produto automotivo requer funcionamento dessa dinâmica visual apresentada por este Esquema Gráfico conforme dissertação sobre particularidades deste tema.

\section{Aspectos Conclusivos}

A abordagem feita sobre o Esquema Gráfico, delimitou a importância do design instrucional quanto à sua serventia perante modelos elaborados no campo das Engenharias, por exemplo. A demonstração teórica do presente artigo serviu para o entendimento do produto visual, e a demonstração conceitual na parte dos Resultados prestou para uma colaboração prática de como o designer pode apresentar soluções a cerca de uma demanda acadêmica, no caso, um gráfico tão somente dado à existir por conta da necessidade de classificação de vários conteúdos. Estes, por sua vez, advindos de diferentes fontes de informação: Engenharia, Gestão, Marketing e Design demonstraram que a interdisciplinaridade pode ser traduzida numa leitura visual formada por elementos gráficos definidos por aspectos decisórios da área do design instrucional.
Realização:

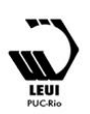




\section{$16^{\circ}$ \\ ERGODESIGN USIHC CINAHPA}

$16^{\circ}$ Ergodesign - Congresso Internacional de Ergonomia e Usabilidade de Interfaces Humano Tecnológica: Produto, Informações Ambientes Construídos e Transporte

$16^{\circ}$ USIHC - Congresso Internacional de Ergonomia e Usabilidade de Interfaces Humano Computador

CINAHPA | 2017 - Congresso Internacional de Ambientes Hipermídia para Aprendizagem.

\section{Referências Bibliográficas}

BATEY, Mark. O significado da marca: como as marcas ganham vida na mente dos consumidores. $1^{\text {a }}$ edição - Rio de Janeiro: Best Business, 2010.

BRUNNER, Robert; EMERY, Stewart. Gestão Estratégica do Design: como um ótimo design fará as pessoas amarem sua empresa. São Paulo: M.Books do Brasil Editora Ltda, 2010.

CARDOSO, Rafael. Design para um mundo complexo. São Paulo: Cosac Naify, 2012.

ESQUEF, Marcos. Desenho Industrial e desenvolvimentismo: as relações sociais de produção do design no Brasil. $1^{a}$ edição - Rio de Janeiro: Synergia, 2011.

KRUCKEN, Lia; COSTA, M.D.; Design no processo de criação de valor nas organizações: $o$ uso estratégico de gráfico. In: Anais do II Congresso Internacional de Design da Informação, 2005, São Paulo.

MONT'ALVÃO, Claudia; DAMAZIO, Vera. (Organizadoras). Vários autores. Design, ergonomia e emoção. Rio de Janeiro: Mauad X FAPERJ, 2008.

PINHEIRO, Tennyson. Design thinking Brasil: empatia, colaboração e experimentação para pessoas, negócios e sociedade. Rio de Janeiro: Elsevier, 2011.

VIEIRA, Leandro do Nascimento. Proposta de Instrumento por atributos informados pelos consumidores automotivos: uma busca por fatores de valorização da marca pela satisfação com o produto.108f. Dissertação. Universidade Federal Fluminense. Escola de Engenharia, 2013 (CDD 658.812) 